\title{
Latent TB Detection and Isolation of MDR TB Bacteria in, MP, India
}

\author{
Bajpai $I^{1}$, Shashank Monika ${ }^{1}$, Gaur Ravi ${ }^{1}$, Kothari Vinita ${ }^{2}$ and Deva Rupal ${ }^{{ }^{*}}$ \\ ${ }^{1}$ Oncquest laboratories Itd., New Delhi, India \\ ${ }^{2}$ Central lab, Oncquest, Yashwant Plaza, Indore, MP, India
}

*Corresponding author: Deva Rupal, Oncquest Laboratories Itd., New Delhi, India, Tel: +91- 8817108478; E-mail: rupal.deva@gmail.com

Received date: September 21, 2015; Accepted date: October 23, 2015; Published date: October 30, 2015

Copyright: @ 2015 Bajpai I, et al. This is an open-access article distributed under the terms of the Creative Commons Attribution License, which permits unrestricted use, distribution, and reproduction in any medium, provided the original author and source are credited.

\section{Abstract}

Aim: Tuberculosis which is an infectious disease caused by $M$. tuberculosis causing pulmonary and extra pulmonary tuberculosis in clinical suspects in Indore and region around central state of India by IGRA methods. In India, TB which is declared to be 'notifiable disease of the nation' by the RNTCP since 2012. We wanted to analyze present state of existence of the same in our city Indore and region around. We wanted to study the present strata of IGRA detected in population of Indore in MP correlating with the Mycobacterium isolates in our laboratory, though the protocol of DOTS have been followed in the country.

Experimental design: In present study, we tested clinical suspects using microbiology biology cultivation method and ELISA method for IGRA in Indore for Mycobacterium tuberculosis in the clinical suspects in our Indore lab, MP, India.

Place and duration: The study was one in Central lab-Oncquest India Ltd. in Indore between period 2012 to 2014.

Methodologies: The present study included 135 patients, including 49 male, and 86 female patients. We used developed TB-TMA method (Oncquest, Ltd.) to detect infection of clinical suspects and utilized culture susceptibility test to detect drug resistance in infecting Mycobacterium causing tuberculosis, tested at Central lab-Oncquest Itd. in India using microbiological methods. The method of drug resistance in Mycobacteria was performed using microbiology methods of drug resistance as described by Songara P, 2015.

Results: We found $53 \%$ samples to be positive from male group compared to $29 \%$ from female group of patients. We could isolate Mycobacterium sp from various clinical suspects using basic microbiology and cultivation methods. Were found $41.6 \%$ Mycobacterium to be sensitive to sensitive to INH 36.65 to RIF, 23.3 to PYRA, 305 to ETHM, $25 \%$ to STREPTO isolated from various samples from clinical suspects.

Conclusion: We were able to detect M. tuberculosis and determine their drug resistance in Mycobacterium method by MDR sure method.

Keywords: Tuberculosis; Drug-resistance

\section{Abbreviation}

TB: Tuberculosis; MTB: Mycobacterium tuberculosis, ATT: Antituberculosis Treatment; INH: Isoniazid; RIF: Rifampicin; PYRA: Pyrazinamide; ETHAM: Ethambutol; STREPTO: Streptomycin. BAL: Broncho Alveolar Levage; MDR sure: Molecular test for Multi Drug resistance Test for $1^{\text {st }}$ line of drugs against Mycobacteria TB; TMA: Transcription Mediated Amplification

\section{Introduction}

Tuberculosis (TB) is a chronic infectious disease, caused by Mycobacterium, having high morbidity and serious health implications in infected individuals (World health Organization, 2013). TB is mainly a pulmonary disease, which may also spread out of respiratory system into the bloodstream, establishing itself in extrapulmonary organs and becoming deadly [1]. It may further lead to its establishment in body as latent state in infected person persisting for years; latent dormant bacteria are capable of revoking later in life. The occurrence of $\mathrm{TB}$ disease is as much as one in five registered $\mathrm{TB}$ patients [2]. This disease occurs mainly in people, having impaired immunity and is found to commonly co-occur among patients infected with HIV infection. In women, the TB is found to be associated, during pregnancy and often contributes to infertility and maternal mortality $[3,4]$. TB disease not only impairs health, but also the socioeconomic status and the development of life, perpetuating the poverty cycle. The prevalence of TB in India was studied by the Indian Council of Medical Research, establishing the national program of 'directly observed therapy short course (DOTS) strategy, in India, approved by the World Health Organization (WHO) and the revised national TB control program revised national tuberculosis control program (RNTCP) [5]. In India, since 2012, TB is now declared to be 'notifiable disease of the nation' by the RNTCP [6]. The infection still remains one of the deadliest diseases in the country, and makes it worst with the development of resistance in the strains. Apart from just an increase in occurrence of this disease, there is also increase in spread of multi-drug resistant tuberculosis bacteria (MDR-TB), in the both 
newly diagnosed patients, and previously treated cases. Mycobacterium can establish as latent tuberculosis, a condition, where bacteria stays in the body for a long time asymptomatically, which may revoke later in life causing tuberculosis disease again. Latent TB is normally is non-infectious but the active TB Mycobacterium can get passed to another person, asymptomatically, establishing itself as a chronic lymphatic infection. The bacteria, which can further develop hematogenous spread in lymphatics or other visceral organs as reported earlier [7]. Skeletal tuberculosis are complicated with psoas abscess which are mainly diagnosed using positron emission tomography-computed tomography [8], while the abdominal tuberculosis can also be identified using MDCT enterography [9]. The extra-pulmonary manifestation was also reported in pericardial fluid [10], as osteoarticular TB, the important forms of extra pulmonary TB, have a significant consequence if not recognized early and treated. Involvement of weight bearing joints and spine is also known. In high prevalence areas, young adults are more commonly affected. A high degree of clinical suspicion along with the radiological, microbiologic and biopsy findings are important for diagnosis and starting ATT, is main strategy [11]. New method of fine-needle aspiration cytology (FNAC) and fluid cytology are also demonstrated to be important in detection of extra-pulmonary tuberculosis as described earlier [12-18]. WHO has declared latent tuberculosis as too expensive and unaffordable for patients [19].

The treatment of infected patient with Mycobacterium include, the treatment with first line drugs, including, Isoniazid (INH), Streptomycin (STREP), Rifampicin (RIF), Ethambutol (ETHAM), Parazinamide (PYRA). The infection with Mycobacterium tuberculosis causes TB disease, which is mainly treated, using the regimen of Isoniazid (INH) and Rifampicin (RMP), drugs while non-tuberculosis Mycobacterium, using various combinations of drugs depending on infecting organism and its drug sensitivity. The typical histopathology view of TBC synovitis include caseous granulomas, surrounded by epithelioid histiocytes and multinucleated giant cells. The tissue infected by Mycobacterium (typical or atypical TBC) usually does not give a positive reaction with Ziehl-Nielsen stain. TB organism was found in the patients with the kidney transplant described earlier [13].The TB of prostate is less common when compared with vesiculoseminal and epididymal TB [14], while the cases of ocular and extra ocular TB and 45 cases of isolated ocular TB were earlier identified in Italy. The cases of Mycobacterium induced uvitis also reported [15]. The clinical pictures were of active, bacteria leading to vision threatening cataract were reported [16], while genital tuberculosis leading to infertility in women have been known. Multidrug-resistant tuberculosis (MDR-TB) is tuberculosis disease caused by organisms, which show high-level resistance to drug Isoniazid and Rifampicin, although the bacteria may or may not show resistance to other anti-TB drugs. There is a constant increase in MDR-TB around the world, both among new cases, as well as in the previously treated ones as reported earlier by WHO $[4,18]$. The development of multi drug resistant bacteria (MDR) occurs due to interrupted, usage of antibiotics, by patient, who halts the medicine ragmen upon feeling better or due to lack of affordable drugs sufficient to kill $100 \%$ bacteria. Such organism there by, become resistant, even to the two most powerful antiMycobacterium drugs like INH and RMP. The first-line treatment antiTB drugs may result in further spread of MDR bacteria in the Population [19]. Earlier, we had reported utilization of modern molecular biology methods in conjugation with classical methods for identification of $M$. tuberculosis infection to assist with the judgment for prescription of right therapy for the Mycobacterium infected individual [20], The prevalence of pulmonary tuberculosis in district Jabalpur were also reported [21]. Since the modern molecular biological methods are still very expensive for the patients, in India. We present here with the prevalence detected of the same in this study. India is among 27 MDR-TB countries, we studied prevalence of MDRTB existence in central state of India. India has huge burden of MDRTB and is included among 27 countries, holding high MDR-TB $[1,19]$. The diagnosis of tuberculosis is not still affordable for the general people in India. We used IGRA test to detect test the serum of clinical suspects for release of Interferon upon exposure to Mycobacterium. Diagnosis of latent TB is though difficult, but the treatment of it is required to reduce the global stress due to tuberculosis. Earlier we had demonstrated our findings of $M$. tuberculosis utilizing combination of more cost effective classical microbiology and biochemistry methods, monitoring the growth and cultivation of Mycobacterium. Occurring in tuberculosis in central state of India [20]. Sensitivity for diagnosis and recording the prevalence of Mycobacterium, there drug susceptibility testing in the population infected with Mycobacterium sp. in central state of India, done in our Indore lab. In this work, we utilized interferon gamma release assay (IGRA) by Mycobacterium for detection of Mycobacterium in clinical suspects in year 2014-2015.

\section{Material and Methods}

\section{Study settings}

This study was done at Central Lab Onquest, Indore (MP.), which is a private NABL accredited lab, in Indore, MP. The data presented here with are tested in clinical suspects in population of city and around Indore in January 2014 to June 2015, where we were able to test.

Processing of specimens samples were obtained from the hospitals of Indore, in the laboratory in a cold box and were processed on the same day or were kept at $+4^{\circ} \mathrm{C}$ in refrigerator, until their processing was done. The tissue samples were first decontaminated using $\mathrm{N}$ acetyl-l-cysteine, $2 \%$ sodium hydroxide and sodium citrate, PBS ( $\mathrm{pH}$ 6.8). As described earlier by Deva $\mathrm{R}$ et al. 2014, in short, we tested a total of samples from TB suspects in Indore and its surrounding region is presented, herewith in this report, in parallel we tested the serum samples for IGRA using ELISA. Patient demographic data like age, gender, address were obtained. We tested serum from clinical suspects were initially to screen them for tuberculosis infection by IGRA method. We tested the samples in our lab for detection of causative agent using the method developed by us as described earlier [21-32]. The tests were performed, the samples used included Sputum, BAL, pus, peritoneal fluid, pleural fluid, lymph node from clinical suspects using microbiological cultivation method and IGRA analysis of serum from clinical suspects done with the consent of patient under Medical supervision, according to guidelines for good clinical laboratory practice (GCLP) in our NABL (National board for accreditation for testing and calibration for laboratory.

\section{Statistical analysis}

Comparision of IGRA test was carried out by using chi-square $\left(\chi^{2}\right)$ and probability $\mathrm{P}$-value $<0.05$ was considered significant.

\section{Results}

In year 2014 to 201549 male samples were analyzed and 86 female samples blood samples were analyzed for IGRA out of them 535 males and $29 \%$ females showed positivity of IGRA test as shown in Table 1. 
We were able to isolate Mycobacterium from $30.4 \%$ isolates from sputum samples, extra-pulmonary samples $14.8 \%$, around $6 \%$ from fluids as shown in Table 2.
We found $53 \%$ samples to be positive from male group compared to $29 \%$ from female group of patients as shown in Table 1.

\begin{tabular}{|c|c|c|c|c|c|c|}
\hline Age (Years) & $\begin{array}{c}\text { Total Male } \\
\text { Samples Tested }\end{array}$ & No. of Male Negative & No. of Male Positive & $\begin{array}{c}\text { Total Female Samples } \\
\text { Tested }\end{array}$ & $\begin{array}{l}\text { No. of Female } \\
\text { Negative }\end{array}$ & $\begin{array}{l}\text { No. of Female } \\
\text { Positive }\end{array}$ \\
\hline $1-14$ & & 3 & 0 & & 2 & 2 \\
\hline $15-24$ & & 7 & 5 & & 17 & 8 \\
\hline $25-39$ & & 8 & 4 & & 37 & 5 \\
\hline $40-54$ & & 6 & 7 & & 1 & 4 \\
\hline $50-60+$ & & 1 & 5 & & 4 & 5 \\
\hline Not known & & 1 & 2 & & 0 & 1 \\
\hline Total & 49 & 26 & $23(53 \%)$ & 86 & 61 & $25(29 \%)$ \\
\hline
\end{tabular}

Table 1: Age distribution of detected Mycobacterium test by IGRA method in patients' blood sample.

\begin{tabular}{|c|c|c|c|c|}
\hline Number & Type of sample & Total no. (\%) & Sample & Total number \\
\hline 1 & Pulmonary & Pulmonary $115(30.4 \%)$ & Sputum \\
\hline 2 & Pulmonary & & Broncheo Alveolar Levage & 47 \\
\hline 3 & Extra pulmonary & $20(14.8 \%)$ & Pus \\
\hline 4 & Extra pulmonary & & $\begin{array}{c}\text { Peritoneal fluid, Pleural fluid, Lymph } \\
\text { node }\end{array}$ \\
\hline
\end{tabular}

Table 2: Isolation of Mycobacterium sp from various clinical suspects using microbiology methods.

We could detect Mycobacterium from different samples from clinical suspects. As shown in Table 2, 30.4\% of cultures were associated with pulmonary tissue and 14.8 with extra pulmonary tissues, while pulmonary samples were analyzed using sputum as test sample. To clarify that the population was associated with infections with drug resistant Mycobacterium we checked the drug sensitivity of samples, which had come to our lab for diagnosis. From various samples we found the drug sensitivity pattern of Mycobacterium as shown in Table 3.

\begin{tabular}{|c|c|}
\hline Drugs sensitivity & Total Number of Resistant Bacteria Isolated Form the Population of Indore \\
\hline INH & $25(41.6 \%)$ \\
\hline RIF & $22(36.66 \%)$ \\
\hline PYRA & $14(23.3 \%$ \\
\hline ETHAM & $18(30 \%)$ \\
\hline STREPTO & $15(25 \%)$ \\
\hline
\end{tabular}

Table 3: Drug sensitivity pattern of MTB isolates to anti tubercular (ATT) drugs.

\section{Discussion}

We analyzed and quantified the interferon gamma release against Mycobactrium in serum samples of clinical suspects of tuberculosis. We found $46 \%$ of serum positive patients by IGRA method. The test also indicates suspects reactivity to Mycobacterium tuberculosis. We found about $29 \%$ of female patients had reacted positively when the serum was tested. IGRA is an indirect test for infection of Mycobacterium which might get un identified by classical microbiological methods IGRA test cannot be used for measurement of tuberculosis diagnostic infection. Being an endemic infection in country [33] the regimen of RIF with ISO was proposed for latent infection as this treatment can be hazardous. It is important to diagnose the patients still having latent infection and also the patients having MDR infection to be cured before they stop any further spread of bacteria in population with developed strains of Mycobacterium. As shown in Table 2 we found association 68 isolates form sputum, 47 from BAL, 15 from extra pulmonary samples, including 14 from pus, 6 from peritoneal fluid, pleural fluid, and lymph nodes as shown in Table 
2 for analysis of IGRA results we correlated the occurrence of and their drug sensitivity in culture in presence of different antibiotics. We found $41.6 \%$ bacteria sensitive to INH, $36.66 \%$ to RIF, $23.3 \%$ to PYRA, $30 \%$ ETHAM and $25 \%$ to STREPTO. The patients were needed to be under strict medical completely to hold the establishment of bacteria to dormant latent infectious disease establishment to eliminate tuberculosis completely the tuberculosis of latent infection should be encouraged, apart from encouraging patient if infected by resistant strain to complete regimen. Resazurin Tube Method: rapid, simple, and inexpensive method for detection of drug resistance in the clinical isolates of Mycobacterium tuberculosis [34], evidence based management of drug resistant tuberculosis was put forwarded [35] and intensive therapy for treatment of latent TB was suggested [36] which intrigued us to study the existence IGRA in clinical suspects in population of Indore and the region around presented in this publication.

\section{References}

1. World Health Organization (2013) Global tuberculosis report.

2. Winn WC, Allen SD, Janda WM, Koneman EW, Schreckenberger PC, et al. (2009) Color Atlas and Textbook of Diagnostic Microbiology | LWW. (6thedn), Lippincott Williams \& Wilkins, New York.

3. Rozati R, Roopa S, Rajeshwari CN (2006) Evaluation of women with infertility and genital tuberculosis. 56: 423-426.

4. Halder A, Jose R, Vijayselvi R (2014) Maternal mortality and derivations from the WHO near-miss tool: An institutional experience over a decade in Southern India. J Turk Ger Gynecol Assoc 15: 222-227.

5. Goel MM, Budhwar P, Jain A (2012) Immunocytochemistry versus nucleic acid amplification in fine needle aspirates and tissues of extrapulmonary tuberculosis. J Cytol 29: 157-164.

6. Sharma SK, Mohan A, Chauhan LS, Narain JP, Kumar P, et al. (2013) Contribution of medical colleges to tuberculosis control in India under the Revised National Tuberculosis Control Programme (RNTCP): lessons learnt \& challenges ahead. Indian J Med Res 137: 283-294.

7. Genç B, Solak A, Mayda A, Sen N (2013) Isolated tuberculous tenosynovitis of the anterior tibial and extensor digitorum longus tendons. J Clin Imaging Sci 3: 37.

8. Kimizuka Y, Ishii M, Murakami K, Ishioka K, Yagi K, (2013) A case of skeletal tuberculosis and psoas abscess: disease activity evaluated using 18 F-fluorodeoxyglucose positron emission tomography-computed tomography. BMC Med Imaging 13: 37.

9. Kalra N, Agrawal P, Mittal V, Kochhar R, Gupta V, et al. (2014) Spectrum of imaging findings on MDCT enterography in patients with small bowel tuberculosis. Clin Radiol 69: 315-322.

10. Lee VYC, Wong JTh, Fan HC, Yeung VTF (2012) Tuberculous pericarditis presenting as massive haemorrhagic pericardial effusion. BMJ Case Rep 2012.

11. N A, Ahmad F, Huda N (2013) Osteoarticular tuberculosis-a three years' retrospective study. J Clin Diagn Res 7: 2189-2192.

12. Narayana Reddy RA, Narayana SM, Shariff S (2013) Role of fine-needle aspiration cytology and fluid cytology in extra-pulmonary tuberculosis. Diagn Cytopathol 41: 392-398.

13. Suthar AB, Rutherford GW, Horvath T, Doherty MC, Negussie EK (2014) Improving antiretroviral therapy scale-up and effectiveness through service integration and decentralization. AIDS 28: S175-185.

14. Boubaker K, Gargah T, Abderrahim E, Abdallah TB, Kheder A (2013) Mycobacterium tuberculosis infection following kidney transplantation. Biomed Res Int 2013: 347103.

15. Cho YS, Joo KJ, Kwon CH, Park HJ (2013) Tuberculosis of testis and prostate that mimicked testicular cancer in young male soccer player. J Exerc Rehabil 9: 389-393.

16. Scheepers MA, Lecuona KA, Rogers G, Bunce C, Corcoran C, et al. (2013) The value of routine polymerase chain reaction analysis of intraocular fluid specimens in the diagnosis of infectious posterior uveitis. ScientificWorldJournal 2013: 545149.

17. Mehta S (2013) Clinical utility of 18 Fluorodeoxyglucose (FDG)-PET/CT scans in patients with suspect ocular tuberculosis. Indian J Ophthalmol 61: 603-605.

18. Ormerod LP (2005) Multidrug-resistant tuberculosis (MDR-TB): epidemiology, prevention and treatment. Br Med Bull 73-74: 17-24.

19. WHO (2010) Executive summary Multidrug and extensively drugresistant TB (M/XDR-TB) 2010. World Health Organisation.

20. Rupal D, Prafulla S, Sushma N, Vinita K, Atul MK, et al. (2014) An interdisciplinary parallel methodological approach for the diagnosis of tuberculosis in the Central state of India. IOSR-JDMS 13: 70-77.

21. Songara P, Deva R, Bajpai IS, Nema S, Kothari V (2015) Drug Resistance Patterns of Mycobacterium Tuberculosis-Isolates from Indore, India. British Journal of Medical and medical research 10: 1-6.

22. Rao VG, Bhat J, Yadav R, Gopalan GP, Nagamiah S, et al. (2012) Prevalence of pulmonary tuberculosis--a baseline survey in central India. PLoS One 7: e43225.

23. Mackie \& McCartney (1996) Practical Medical Microbiology. Churchill Livingstone, (Elsevier), Netherlands.

24. Manca C, Paul S, Barry CE 3rd, Freedman VH, Kaplan G (1999) Mycobacterium tuberculosis Catalase and Peroxidase Activities and Resistance to Oxidative Killing in Human Monocytes In Vitro. Infect Immun 67: 74-79.

25. Dixit P, Singh U, Sharma P, Jain A (2012) Evaluation of nitrate reduction assay, resazurin microtiter assay and microscopic observation drug susceptibility assay for first line antitubercular drug susceptibility testing of clinical isolates of M. tuberculosis. J Microbiol Methods 88: 122-126.

26. Srivastava I, Bhatambare GS, Deshmukh AB, Bajpai P, Bajpai T, et al. (2014) Genital Tuberculosis: Evaluating Microscopy , Culture , Histopathology and PCR for Diagnosis All Play Their Role. Int J Curr Microbiol App Sci 3: 439-445.

27. Goel G, Khatuja R, Radhakrishnan G, Agarwal R, Agarwal S, et al. (2013) Role of newer methods of diagnosing genital tuberculosis in infertile women. Indian J Pathol Microbiol 56: 155-157.

28. Ameeruddin NU, Luke Elizabeth H (2014) Impact of isoniazid resistance on virulence of global and south Indian clinical isolates of Mycobacterium tuberculosis. Tuberculosis (Edinb) 9: 557-556.

29. Schluger NW (2015) Diagnosis, treatment, and prevention of drugresistant tuberculosis. Wolters Kluwer, Netherlands.

30. Chang KC, Leung CC, Yew WW, Leung EC, Leung WM, et al. (2012) Pyrazinamide may improve fluoroquinolone-based treatment of multidrug-resistant tuberculosis. Antimicrob. Agents Chemother 56: 5465-5467.

31. Jain K, Desai M, Solanki R, Dikshit RK (2014) Treatment outcome of standardized regimen in patients with multidrug resistant tuberculosis. J Pharmacol Pharmacother 5: 145-149.

32. Bonura C, Gomgnimbou MK, Refrégier G, Aleo A, Fasciana T, et al. (2014) Molecular epidemiology of tuberculosis in Sicily, Italy: what has changed after a decade? BMC Infect Dis 14: 602.

33. Hemvani N, Patidar V, Chitnis DS (2012) In-house, simple \& economical phage technique for rapid detection of rifampicin, isoniazid, ethambutol, streptomycin \& ciprofloxacin drug resistance using Mycobacterium tuberculosis isolates. Indian J Med Res 13: 783-787.

34. Patil SS, Mohite ST, Kulkarni SA, Udgaonkar US (2014) Resazurin tube method: rapid, simple, and inexpensive method for detection of drug resistance in the clinical isolates of mycobacterium tuberculosis. J Glob Infect Dis 6: 151-156.

35. Pai M, Rodrigues C (2015) Management of latent tuberculosis infection: An evidence-based approach. Lung India 32: 205-207.

36. Menzies D, Al Jahdali H, Al Otaibi B (2011) Recent developments in treatment of latent tuberculosis infection. Indian J Med Res 133: 257-266. 